\title{
Discontents of Globalization and Post Traumatic Stress in Hamid's Exit West
}

\author{
* Dr. Zahoor Hussain, Lecturer \\ ** Dr. Muhammad Ahsan, Lecturer (Corresponding Author) \\ *** Uzma Akram, MPhil Scholar
}

\begin{abstract}
The core objective of the work was to investigate and reconnoiter globalization and its heinous impacts on modern society. Xenophobia and hostility towards migrants are some of the greatest issues faced by the migrant people in this globalized world. As a result, they have suffered from psychological trauma, post-traumatic stress disorder, which may follow a variety of traumatic events. The researcher tried to analyze the discontents of globalization and post-traumatic stress concerning the fictional world created by Mohsin Hamid in his novel Exit West (2017). This study was based on qualitative research, interpretation of the novel in the light of globalization and its impacts in the present scenario. For thematic analysis, the model of acculturation proposed by Berry (2006) had been adopted. The researcher mainly focused on the characters and the impact of migration on these characters in the context of globalization and psychological trauma.
\end{abstract}

Keywords: Globalization, Post-traumatic stress, Acculturation, Migration Introduction

Globalization has made complex interconnections over the world. One of the effects of globalization can be visible in the cities over the world which has all of sudden become multicultural and cosmopolitan. This neocolonialism has a noticeable effect, not through violent strategies of politics but by quietly and slowly modifying the culture. In any society, migration and globalization are two main aspects. Migration is a worldwide phenomenon where inhabitants shift from one area to another for different reasons. In migration, immigrants leave their country looking for better living and occupation for themselves and their family. It frequently contains deconstruction as well as reconstruction of migrants' cultural aspects.

People have been traveling from the day when they used to live on the river's bank or in caves. They needed to migrate to better places when the indications of lava or flood were seen. They did not have permanent land. While in the modern period, all their travels cannot be considered as the diaspora. Previously, a huge mass development was begun migration towards various portions of the world. For the most part, Asians moved towards the countries of Europe. Dislocation of place, of culture and self, has been connected with diaspora and post-colonialism, and in the late $20^{\text {th }} \mathrm{C}$ as well as early $21^{\text {st }} \mathrm{C}$, these dislocations have been exacerbated by the quick beginning of globalization and transnationalism.

People who had to face forced migration are more likely to have experienced a sort of trauma that would lead them to post-traumatic stress disorder. Trauma exposure and post-traumatic stress are associated with complex psychiatric presentations and impairment in dislocated people. Adversative influences of migration on mental or cerebral health are well well-known and are multiplied in these circumstances by the traumatic happenings of migration along with social weaknesses that follow. Porter and Haslam (2005) discovered pre-displacement and post-displacement dynamics connected with the mental health of migrated people.

The present study is qualitative. For the thematic analysis of the novel Exit West, the model of acculturation by Berry (2006) has been adopted. The research is designed on the concepts of Berry's model of acculturation (2006) which is based on dimensions of assimilation, separation, integration, and marginalization. The concise objective of this research paper is to analyze the situation that makes

\footnotetext{
* Department of English, Bahaudin Zakariya University, Layya Campus, Pakistan

Email: zahoor linguist@bzu.edu.pk

** Department of English, Ghazi University Dera Ghazi Khan, Pakistan. Email: mahsan@gudgk.edu.pk

*** ISP, Multan, Pakistan
} 
the people take an exit, the difficulties faced by the people because of their exodus, and how the migration and globalization affect the major characters in the novel.

\section{Literature Review}

We are living in an era where global colonization, border crossings, and universal media are flourishing rapidly. Appadurai (2006) claimed that globalization has resulted in intricate interconnections and acquaintances throughout the world. As a result, people flee across borders, economy, and media exchanges are interconnected worldwide, and ethnicity has attained mobility that creates struggle and new civilization of conflicts among the people. "Globalization has enhanced links and acquaintances among people and their ideas, values, and ways of life in unique ways."(United Nation Development Program, 2004, p. 85). Globalization and migration are interconnected with each other and can be considered the two significant features of a society. Migration is a general phenomenon and human beings have been shifting from one place to another since the beginning when they used to live in the caves. In the past, a huge number of people migrated to different parts of the world for better future and economic conditions. Lavie and Swedenberg (1996) asserted that the dispersion of billions of immigrant refugees, laborers, and professionals from the "Third World" to the "First World" and the creation of several ethnic enclaves of migrants is the most significant aspect of the $20^{\text {th }}$ century. Since 1980, the term diaspora has been prevalent in European countries.

At present, globalization is an essential factor of social renovation all over the world. Moslund (2010) argued that a large number of local, national, and transnational migrants are on the move, crossing cultural and national borders. Nation-states encourage certain types of mobility while restricting others. As a result, new Diasporas are created and questions of belonging and home require negotiation and transformation. Nayar (2010) said that the visible impact of globalization can be found in the metropolises across the world which suddenly become cosmopolitan and multicultural. This is 'neocolonialism' making itself felt slowly and quietly through the market as well as culture.

The increasing globalization and socio-economic differences between developed and underdeveloped countries have contributed as "push" factors in the migration of inhabitants from underdeveloped countries to the developed ones for a better life and future. "Acculturation is not accomplished without the aspect inters cultural amalgamation; so this stipulation is centrally significant" (Padilla, 1980, p. 11). The reason behind the process of migration is extremely significant, and frequently decides the rate of motivation towards the acculturative process. For adults, their motivation for immigration might be improved their financial condition, escape them from political or ethnic maltreatment. (Bornstein \& Cote, 2006). There are both negative and positive effects of migration upon the countries. It is obvious that presently not a single country exists which is not affected by migration either as a receiver or sender. Bhugra (2003) opined that immigrants have to choose whether o to depart their state of origin or not, it is a personal choice. They depart a civilization for economic, stirring, or enforced purposes. There must be some push or pull factors at the back of this migration, and this further shows the way to the nature of retort an individual has towards a new community. The impact of voluntary or involuntary migration is quite significant to comprehend while evaluating the after-effects of migration.

People that flee forcibly will frequently have to face difficulties with acculturation. It has been observed that newly arrived refugees share experiences of pain, a revelation to biased terror, mass execution, or constant torture. In the case of forced migration, the pre-migration aspects might become the cause of complexity and eventually influence the amendment to the host state. When an individual with higher education is enforced to migrate, he/she is forced to end up doing a subordinate job. This will affect their self-worth and also affect the process of adjustment to new society vice versa (Bhurgra, 2003). Gibson (2001) concluded in his work that refuges are usually expected that their settlement in host land is temporary. For such immigrants, their expectation is mainly concerned with their immediate return to their state of origin. Though, if immigrants voluntarily left a society, then they are liable to adapt to the customs of the host land or society. They could also persuade their progeny to act in the same manner, with swift acculturation as a source for attaining their objectives.

The attack of 9/11 had a traumatic impact on the Muslim community in western countries. Alvi (2014) revealed that Muslim Americans had to face suspiciousness and hostility after the tragic attacks of 9/11. Many of them became the subject of fear and physical and mental trauma. According to the Human Rights Watch Report (2002), the new immigration policies of the federal government in America after 9/11 specifically targeted the Muslim community. These policies allowed the 
confinement of about 1200 individuals of Muslim, Arab, and South Asia. Peek (2005) analyzed in his work that in the United States many people who share the same religious or cultural background as the attackers became the subject of hostility after the tragic event of September 11. Bradford (2009) claimed that Muslims, Arabs as well as South Asians, and other people who were erroneously supposed to be Muslim experienced asset damage, terrorization, harassment, prejudice, ethnic and religious profiling, vocal and physical attacks.

Alam (2019) in his research work stated that the hegemonic attitude of the society has been shown well in the novels of the 21 st century where religious stratification is seen making its clear ways of depiction in the post 9/11 narrative. Moreover, the fiction of the twenty-first century exhibits 9/11 as a major and key representation of themes, plots, characters, discussion, and dialogues. 9/11 is applied as a semiotic and symbolic literary device of fiction writing and narrative in global literature. The literature of this particular period is reflected with the profound processing of 9/11 and its political, social, cultural, and psychological impact, and its effects as terror and trauma. The literature of this particular period presents different dimensions of the incidents and happenings, person and society, beliefs and believers, ideology and action. The post $9 / 11$ fiction also presents other aspects of life, incidents, situations, conditions, issues, problems of people, and society. The literature of this period focuses on major issues and problems of identity and fear which has been developed after the incident. The post 9/11 fiction reflects the issues of an identity crisis, cross-cultural conflict, sense of insecurity, and fear.

A deep study of the above dimensions and terms leads us to the point that as a consequence of immigration, people come into direct contact with various cultures and ethnicities and this gives rise to the notion of acculturation. Graves (1967) introduced the notion of psychological acculturation. He referred this notion to the change in an individual, who is in the condition of mutual ethical contact, as an outcome of effects of both the external culture as well as the changing culture to which the individual belongs.

\section{Research Methodology}

Berry (2006) proposed that the process of acculturation continues as per how much the individual at the same time takes part in the new society's cultural life and keeps up their unique cultural identity. The synchronous contribution and conservation of the two societies may prompt four distinct results which Berry called integration, marginalization, assimilation, and separation. Collectively, these four results are referred to as "acculturation strategies." Meanwhile, in a continuous process, acculturation, a person may accept various strategies on various occasions, and to manage diverse life issues. These various strategies ought not to be considered as "additive," prompting where an individual can think about a person as being completely "integrated." On the other hand, these techniques could be assumed as stages which a person may often ignore, utilizing a few procedures at some random time. Berry (2006) opines that the meeting of different cultures and the consequential changes are collectively known as acculturation. History shows that many people around the world have moved or migrated for several reasons, either better livelihood, to do business, to conquer and colonize, or for fun and adventure. These actions have resulted in the cultural contacts of people from different backgrounds. Due to these cultural contacts, the changes in the original culture and life of people have produced which led to the formation of new societies. He is of the view that the changes that take place at the group level and individual level are quite different. At the group level, the changes might be in social, political, and economical patterns. At the individual level, the changes might be in the identity, values, behaviors, and attitudes of the people.

The process of cultural and psychological changes due to different cultural contact has resulted in the formation of societies with different religious, cultural, and linguistic patterns. Such kind of societies is termed as plural societies by Berry (2006). He formulates two implicit models of plural societies which are presented in Figure 1. 
Figure 1. Two implicit models of culturally plural societies

\section{MELTING POT}

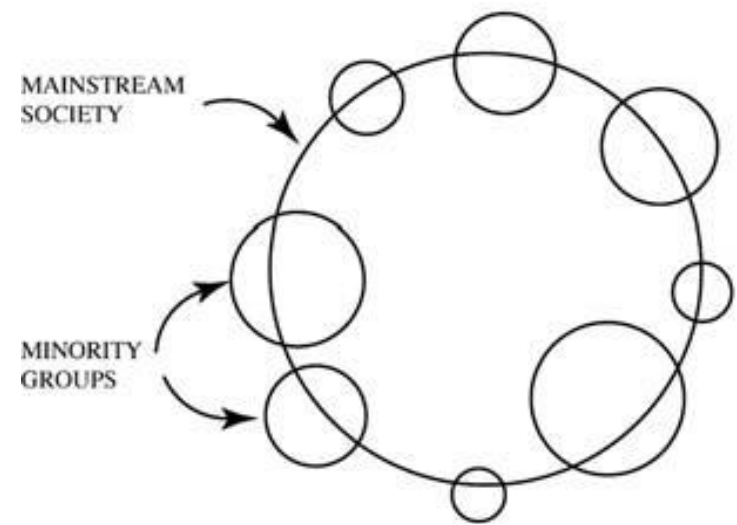

CULTURAL PLURALISM

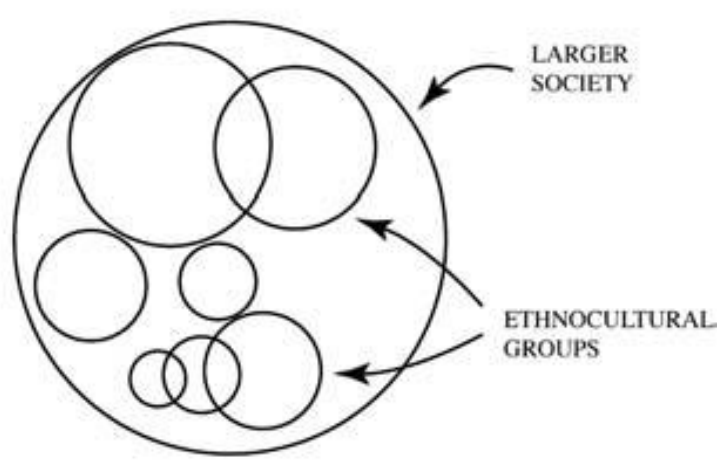

(Adapted from: The Cambridge handbook of Acculturation Psychology by D. L. Sam and J. W. Berry 2006, P.28)

In the first implicit model (the mainstream-minority), there is a melting pot; with a single mainstream or dominant society, on the edges of which are the various minority groups. Generally, it is assumed that such kinds of minority groups or societies should be absorbed in mainstream society in such a manner that they vanish. Their ethnic stability is denied and this amalgamation is the merely acceptable source for their contribution to society. On the other hand, if such absorption into a homogeneous society is not accomplished, then the groups on the boundaries become marginalized. The second implicit model is multicultural, as shown in fig 1 , in which there is a mixture of ethnocultural groups. In this model groups and individuals maintain their cultural identity and the sense of cultural continuity due to which they participate in the social structure of larger society. This conception of the larger society is quite different from that of the mainstream, in which the dominant group maintained the key features of the society.

In plural societies, there are different kinds of groups of individuals each one belonging to different cultural backgrounds. Different varieties of groups in plural societies are presented in figure 2.

Figure. 2 Varieties of groups in plural societies

\begin{tabular}{llll}
\hline Mobility & & Voluntariness of Contact & \\
& & Voluntary & Involuntary \\
\hline Sedentary & Ethnocultural Group & Indigenous People \\
Migrant & Permanent & Immigrants & Refugees \\
& Temporary & Sojourners & Asylum Seekers \\
\hline
\end{tabular}

(Adapted from: The Cambridge handbook of Acculturation Psychology by D. L. Sam and J. W. Berry 2006, P.30)

Among these groups are indigenous people, also known as longest-term residents, who have "always been there" in the sense that their roots go way back. They have been seen as a minority group within a larger society. They are involuntary as well as sedentary. Ethnocultural groups are voluntary participants of their contemporary societies with the sense of their cultural heritage. Other groups migrate for residence (either temporarily or permanently) in another society. Among these immigrants are the permanent participants in a new society whereas sojourners are the temporary participants for a set purpose such as students, diplomats, aid workers, etc. Involuntary migrants are refugees and asylum seekers now often known as "forced migrants".

Berry has proposed four acculturative strategies i.e. assimilation, integration, separation, and marginalization. Assimilation is a strategy in which individuals do not wish to retain their original cultural identity and seek out interaction with other cultures. In contrast, if individuals retain their original cultural identity as well as keep away from interaction with other cultures then separation strategy is defined. When individuals show interest in maintaining their original cultural identity along with their interactions with other cultures then the strategy of integration comes into consideration. Marginalization strategy can be explained in a situation when individuals do not show interest in retaining their original cultural identity and also do not seek to have interactions with the 
new or other cultures. Among these strategies, integration leads to the proper amalgamation of two or more cultures. Integration strategy is quite helpful in effective cultural and social harmony and individuals who practice this strategy experience fewer difficulties in adaptation. As a result, they have to face less psychological distress in society.

The acculturation model offered by Berry (2006) includes the factors based on political, cultural, economic, and historical perspectives. These aspects are quite helpful in the selection of one of the acculturative strategies of Berry's model. A framework that illustrates the chief features that affect an adaptation of an individual is presented in Figure 3.

Figure 3. Factors affecting acculturative stress and adaptation

Group Level

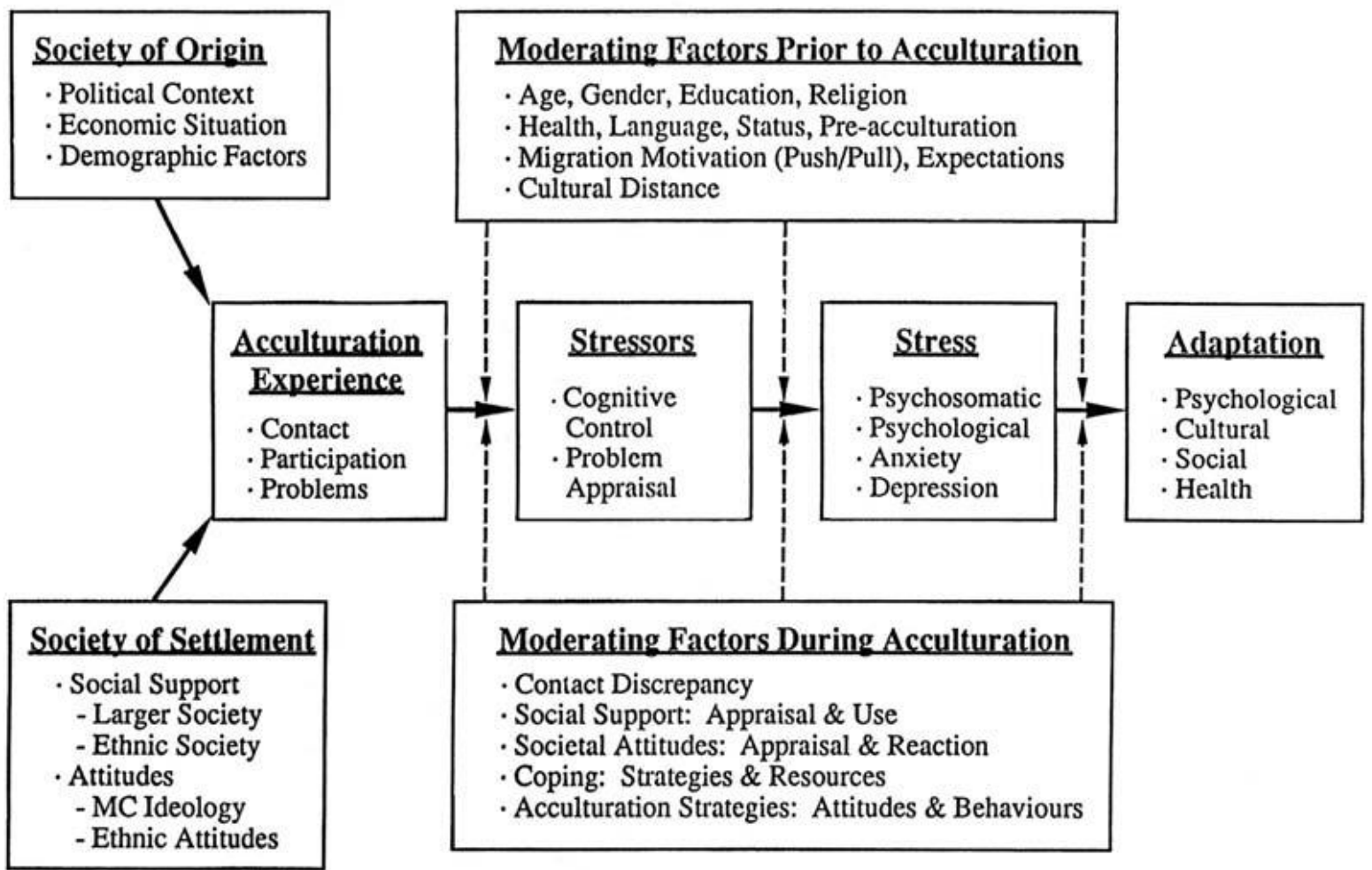

(Adapted from: The Cambridge handbook of Acculturation Psychology by (Sam \& Berry, 2006, P.45)

In Figure. 3. The researchers that on the left, the cultural or group level phenomena are presented as "situational variables". On the right, individual or level of psychological processes is presented as "person variables". By the side of the top are moderating traits that occur preceding acculturation. Laterally at the bottom are the factors that come up throughout the procedure of acculturation. In the mid of the framework, the psychological along with group acculturation phenomena; these movements from left to the right start with cultural contacts and bring about changed in many of their features as social, economic, political structures. These changes greatly affect the individuals going through the process of acculturation and also the process of individual adaptation. The above Fig 3 also provides a framework by combining both structural and process features within which we can discover the various factors which influence the experiences of acculturation. It also contains the living experiences of refugees or migrants in the new host culture or land. In contrast, due to the failure of the process of acculturation cultural relationships are established. These relationships lead to the formation of social attitudes, societal stereotypes, prejudice, and ideology of culture and a sense of justice among two cultures. Thus the improvement of cultural relations shakes the basics of society along with its peace.

The novel Exit West (2017) by Mohsin Hamid has been selected for the data analysis. Further data for the review of literature is collected by interpreting and examining related articles, literature, 
and understanding the ideas of diaspora, globalization, migration, and acculturation given by different theorists.

\section{Data Analysis}

Mohsin Hamid is one of the renowned Pakistani Transnational writers. His recent work Exit West attempts his best in depicting the global immigrant crises along with discontents of globalization in the lives of people of the modern era. The narrative initiates with Saeed and Nadia meeting each other in a town swollen by refugees and is at the bank of war. They meet up in an evening class on "corporate identity and product branding". Saeed is a self-determining sophisticated young man working for a marketing firm and resides with his parents. Nadia, who at all times dress in a black robe works for a corporation and lives single-handedly, a very exceptional thing in their conventional and religious state. Saeed and Nadia fall in love with time as their metropolitan falls prey to fright and aggression.

Forced migration creates a lot of hardships in the lives of the dispersed people. Several natives migrate to other territories for the security of their lives. Hamid tries to reveal a similar dilemma in Exit West. Hamid accounts his story in the era of the past, in an anonymous city that is on the verge of civil fighting. The ambiguity of the city proceeds for universalizing the milieu through which the main characters discover them, and also encourages the reader to visualize the dilemma when how one's native town might alter if subjected to the same scenario. As the condition in the anonymous city gets worse, and a group of militants belonging to an unrevealed group take out the control of the city from government armed forces, the protagonists of the tale, an exquisite young couple, Saeed and Nadia, escape from the state of their birth in seek of safety. The rising hazards were felt by Saeed, "Saeed desperately wanted to leave his city, in a sense he always had, but in his imagination, he had thought he would leave it only temporarily" (Hamid, 2017, p.89). Migration had unpleasant effects on them. "The further they moved from the city of their birth, through space and through time, the more he sought to strengthen his connection to it, tying ropes to the air of an era that for her was unambiguously gone" (Hamid, 2017, p. 187).

Migrants are those who shift from one's state to another state to survive there. According to Merriam Webster's Dictionary, a Refugee is well-defined as "someone who has been enforced to leave one's country because of war or for religious or political reasons". These dynamic reasons are the situations that compel people to flee from their native lands. As in this work of fiction, the major characters and other minor characters leave their homes, parents, family, career, acquaintances, and everything when the circumstances become inappropriate to lead a safe and sound life. Usually, immigrants are coming under the category of economic migrants ate to another state to survive there. One who migrates is identified as an immigrant. Refugees are deprived of proper basic needs such as shelter, food, attire, medicine good water, etc. Those people who are forced to flee will seek out support from helping countries. They construct a house like a thing as a small camp or tent, to live in with accessible resources. Although they are provided with a small part of the land it is not enough for them because they arrive in large numbers. The precise condition of refugees devoid of proper shelter and basic needs is classically depicted as follows in Exit West.

Refugees had occupied many of the open places in the city, pitching tents in the green

belts between roads, erecting lean-tos next to the boundary walls of houses, sleeping

rough on pavements and in the margins of streets. Some seemed to be trying to

recreate the rhythms of a normal life, as though it were completely natural to be

residing, a family of four, under a sheet of plastic propped up with branches and a

few chipped bricks (Hamid, 2017, p. 23).

Technology in the contemporary age offers many 'doors' or 'windows' through which people can cross all types of borders. The use of the internet and social media provides immense access throughout the world and people might be anywhere they desire to be within fractions of a second. They can also move to fictitious places that do not exist at all. As in the case of the protagonists,

In their phones were antennas and these antennas sniffed out an invisible world as if by magic, a world that was all around them, and also nowhere, transporting them to places distant and near, and to places that had never been and would never be... (Hamid, 2017, p. 39).

Saeed and Nadia also utilize modern technology in the sense of being emotionally at places where they desire to be but it is not possible. They stay in contact with their family and are aware of 
what is going on in other states through the same means. Thus telephone acts as an epitome of the doors to cross the fluid boundaries.

The word "war" is a symbol of devastation and catastrophes. This is a pennant of death and bloodsheds. The beginning of the novel" Exit West" by Hamid also shows the diagnostic mood of the major typescript (Nadia and Saeed) that they are affront from each other. War is also a symbol of disconnection that no one can save himself properly during the war. There were the strains of bloodshed in the city that dozens of people taste death in a brawl. The violence was at the peak that the refugees became the sufferer of suicide intimidation. This kind of violence was done for killing the people and dispersal the fear among the citizens. They never thought of diaspora but the situation of the city never supported them till the end. At last, the peace seems them in the diaspora. "The city had yet to experience any major fighting, just some shootings, and the odd car bombing..." (Hamid, 2017, p.2). People saw a lot of murders. The natives were executed in the streets and the houses. A ponyboy was murdered. Nadia's neighbor was beheaded and his blood seems in the corner of Nadia's roof. They saw the dead bodies lynching on the electric towers and signboards. Some were hanged on the trees. The smell of the dead bodies was dreadful. It choked those people who passed from there. The graveyards became shorter and shorter.

Funerals were smaller and more rushed affairs in those days, because of the fighting. Some families had no choice but to bury their dead in the courtyard or at the sheltered margin of the road, it being impossible to reach a proper graveyard... (Hamid, 2017, p.73).

\section{Conclusion}

After reading and analyzing the text, the researcher has found that the central theme of the novel is movement from East to West and from West to East, starting from South to North, from North to North. Exit West is not only concerned with investigating the world's problems in which migrants look for a safe way from their violent countries to the areas of greater stability and wealth. It is additionally inspired by the question of rupture, of destabilization, of unpredictability. Through the novel, the major characters (Saeed and Nadia) are developed and their dissimilarities became increasingly distinctive to further read. The changes they experience were the organizing portion of the study, although they were enlightened through the importance of the places where they live. The connection to their reality in a different city, both Nadia and Saeed, advanced in several ways, and their opposing observations have been conveyed.

The researcher has found that generally, the main objective of the novel was to begin a discussion on migration and refugees. The analysis of data illustrated that the author used the heroes or protagonists to symbolize the experiences of refugees, and how they altered the features and perception (both internally as well as externally) in connection to other people. It has been observed that he did not only wish to demonstrate the experiences of two individual migrants but he wished to represent the grief, depression, and stress of migrants as well. Through the inclusion and creation of various events the major characters were used as a method of demonstrating the fact that all the disturbances which Nadia, as well as Saeed, faced, many people also face the same struggles, trauma, and stress, even though their occurrence is special, it is not unusual.

Global migrations, as well as crisis of refugees, are the outcome of the developing fascination with nationality and other rigid divisive ideas in the whole world. These beliefs were demonstrated risky very early even though they were extensively supported during different anticolonial fights. These fictional borders just help in expanding the struggles in the world which should be replaced and remedied with a new comprehensive ideology. However, the scenario of post 9/11 observed an emphasis on these ideologies in various countries, mainly the primary world. Through Hamid's Exit West, he attempts to get the risk of it and, for a borderless world, he recommends a solution. The crisis of refugees must be managed as a direct conflict of the realities of nationalism and neo-colonialism. Exit West is a tale of deterritorialization. The writer considers that it is the thing that the world and the generations of the future now demand a world without boundaries.

\section{References}

Alam, M. (2019). Globalization and conjectures of fear and identity in select 21st-century novels (Doctoral thesis). Aligarh Muslim University, Aligarh, India. 
Alvi, H. (2014). The diffusion of intra-Islamic violence and terrorism: The impact of the proliferation of Salafi/Wahhabi ideologies. Middle East Review of International Affairs (Online), 18(2), 38.

Appadurai, A. (2006). Fear of small numbers: An essay on the geography of anger. Durham, NC: Duke University Press.Berry, J. W., Poortinga, Y. H., Segall, M. H., \& Dasen, P. R. (2002). Cross-cultural psychology. United Kingdom: Cambridge University Press.

Berry, J. W. (2006). Stress perspectives on acculturation. In D. Sam \& J. Berry (Eds.), The Cambridge handbook of acculturation psychology (Cambridge handbooks in psychology, pp. 43-57). Cambridge: Cambridge University Press.

Bhugra, D. (2003). Migration and mental health. Acta Psychiatrica Scandinavica, 109, 243-258.

Bornstein, M. H., \& Cote, L. R. (2006). Acculturation and parent-child relationships. Mawah, NJ: Lawrence Erlbaum

Bradford, J. W. (2009). American/Muslims: Reactive solidarity, identity politics, and social identity formation in the aftermath Of September $11^{\text {th }}$ (Doctoral dissertation).Harvard University, Cambridge, USA

Gibson, M. A. (2001). Immigrant adaptation and patterns of acculturation. Human Development, 44, 19-23.

Graves, T. D. (1967). Psychological acculturation in a tri-ethnic community. Southwestern Journal of Anthropology, 23(4), 337-350

Hamid, M. (2017). Exit West. New York: Riverhead Books.

Lavie, S. \& Swedenburg, T. (Eds.). (1996). Displacement, diaspora, and geographies of identity. London: Duke University Press.

Moslund, S. (2010). Migration literature and hybridity: The different speeds of transcultural change. New York, NY: Springer.

Nayar, P. K. (2010). Postcolonialism: A guide for the perplexed. London: Continuum.

Padilla, A. M. (1980). Acculturation: Theory, models, and some new findings. Boulder, CO: Westview Press.

Peek, L. A. (2005). The identity of crisis: Muslim Americans after September 11. Colorado, USA: the University of Colorado at Boulder.

United Nations Development program. (2004). Human development report. New York, NY: Oxford University Press. 